\title{
Effects of Preoperative Mean Platelet Volume on Early Outcomes of Patients After Conventional Coronary Artery Bypass Graft Surgery
}

\author{
MD. AMIRUL HASAN ${ }^{1}$, MD. KAMRUL HASAN MILON ${ }^{2}$, MD. ABUL KASHEM ${ }^{2}$, MD. REZAUL KARIM ${ }^{2}$ \\ ${ }^{1}$ Cardiovascular Surgery Unit, Combined Military Hospital, Dhaka, ${ }^{2}$ Dept. of Cardio-Vascular Surgery, National Institute of \\ Cardiovascular Disease (NICVD), Dhaka
}

Address of Correspondence: Lt. Col. Dr. Md. Amirul Hasan, Cardiovascular Surgery Unit, Combined Military Hospital. Dhaka. E-mail: hasancs2008@yahoo.com.

\begin{abstract}
:
An elevated mean platelet volume is associated with increased platelet activation and thus may predict thrombotic events including major cardiac adverse events after CABG surgery. The association of mean platelet volume with in-hospital outcome of patients after coronary artery bypasses grafting surgery was investigated in this study. Preoperative mean platelet volume was obtained prospectively in $8^{\wedge}$ consecutive patients undergoing conventional coronary artery bypass surgery. Postoperative mortality and major adverse events were recorded in the early postoperative Period. Combined adverse events including post operative Myocardial Infarction (MI), arrhythmia, bleeding and death occurred in 27 patients (33.3\%) during the early follow-up. The preoperative mean platelet volume levels were found to be associated with postoperative adverse events $(\mathbf{p}<0.05)$. In multivariate logistic regression models, the preoperative mean platelet voluue levels was found strong independent predictor of combined adverse events after surgery $(O R$ 1.968, $p=0.008)$.
\end{abstract}

Key Words: Conventional coronary artery bypass grafting (CABG), Mean platelet volume (MPV), Combined adverse events

University Heart Journal 2018; 14(1): 24-27

\section{Introduction:}

Recent advances in clinical laboratory techniques have opened new horizons for a better understanding of the role of platelets in thrombosis, immunity, inflammation and angiogenesis. ${ }^{7}$ Platelets play a pivotal role in the development of atherosclerotic lesions, plaque destabilization, and atherothrombosis. ${ }^{3}$

Assessment of platelet function with mean platelet volume (MPV) level gained popularity in recent years. The MPV is a marker of platelet size and activation. It is more reliable measurement of platelet function than the platelet count alone. Increased MPV reflects active and large platelets. Elevated levels of MPV have been demonstrated to be an independent predictor for ischemic vascular events, recurrent $\mathrm{Ml}$ or death from coronary artery disease. ${ }^{2,5,7}$

Coronary artery bypass graft (CABG) is the definitive surgical treatment of the coronary artery disease. In recent years, Overall mortality rate of coronary artery surgery is low, at around $2 \%-3 \%$, although this benefit is offset by a complication rate of $20 \%-30 \%{ }^{1}$

There are limited data emphasizing the association of platelet activation with adverse outcomes following
CABG. ${ }^{4}$ Preoperative elevated MPV level was a strong independent predictor of combined adverse events, postoperative $\mathrm{Ml}$ and major adverse cardiac events (MACE). ${ }^{6}$ Estimation of MPV is an easy and cost effective test. Therefore, within the single center registry of patients undergoing CABG surgery MPV was detected for prediction of outcome.

\section{Materials and Methods:}

An observational prospective analytical study was carried out in the Department of Cardiovascular Surgery, National Institute of Cardiovascular Diseases (NICVD), Dhaka during the period from July 2012 to June 2014. Purposive convenient sampling technique was employed and inclusion criteria was patients undergoing conventional $\mathrm{CABG}$ surgery during the specified period. Exclusion criteria included (1) emergent surgery, (2) redo CABG, (3) off-pump CABG, (4) myocardial infarction within a week, (5) preoperative severe anemia (hemoglobin level $<10 \mathrm{~g} / \mathrm{dl}$ and/or hematocrit level $<$ $30 \%)$, (6) Patients with poor LV function $(\mathrm{LVEF}<30 \%)$ and (7) patients with stroke. The patients were divided into two groups according to normal and elevated MPV at 10.60 femtolitre (fL) cut off level. Baseline clinical 
details and preoperative mean platelet volume were obtained prospectively in 81 consecutive patients. Postoperative mortality and major adverse events were recorded in the early postoperative period. Postoperative outcome variables were (1) Postoprative Ml, (2) arrhythmia, (3) bleeding and (4) Death.

\section{Result:}

Baseline characteristics were recorded in table-1. Mean age of the studied patients were 53.22 \pm 7.88. Among them 70 were male and 11 were female. According to NYHA functional class $39(48.1 \%)$ were found class II and 42(51.9\%) were class III. Maximum patients 69(85.2\%) of this study had triple vessel disease and maximum patients $69(85.2 \%)$ were treated with 3 bypass grafts.

Major adverse events observed early after CABG surgery is shown in table-2. 3 patients $(3.7 \%)$ died during hospital stay, 11 patients $(13.5 \%)$ developed post-operative myocardial Infarction (Ml) and 09 patients (11.1\%) developed post-operative arrhythmia. Major postoperative bleeding (D500 ml) occurred in 15(18.5\%) study patients. Regarding post-operative arrhythmia and post-operative death no significant association found ( $p$ $>0.05$ ). Only strong association of post-operative $\mathrm{Ml}(\mathrm{p}$ $<0.05)$ and post-operative bleeding $(\mathrm{p}<0.05)$ (OR 1.313, $95 \% \mathrm{Cl} 0.352$ to 4.896 and $\mathrm{OR} 1.51,95 \% \mathrm{Cl} 0.350$ to 6.526 respectively).

Univariate analysis showed significant difference of left ventricular ejection fraction (LVEF\%), Mean platelet volume (MPV) and total cardio pulmonary bypass time (CPB) found with adverse events $(p=0.037, p=0.011$, $\mathrm{p}=0.035$ respectively).

Receiver operating characteristic curve of the mean platelet volume (MPV) in the study sample for predicting post CABG adverse events demonstrated an area of 0.738 (95\% Cl, $0.621-0.855)$ under it. At $10.60 \mathrm{fL}$ cut off point sensitivity $77.48 \%$ and specificity $63.6 \%$.

Table-I

Clinical and operative characteristics of patients

\begin{tabular}{|c|c|c|c|c|c|c|c|c|c|}
\hline \multirow{2}{*}{\multicolumn{2}{|c|}{$\begin{array}{l}\text { Patients } \\
\text { Characteristics }\end{array}$}} & \multicolumn{2}{|c|}{ Group A $(n=34)$} & \multicolumn{2}{|c|}{ Group B $(\mathrm{n}=47)$} & \multicolumn{2}{|c|}{ Total $(n=81)$} & \multirow{2}{*}{$\begin{array}{c}5 \mathrm{C} 2 \\
1.463\end{array}$} & \multirow{2}{*}{$\begin{array}{l}\mathrm{p} \text { value } \\
0.230^{\mathrm{NS}}\end{array}$} \\
\hline & & Number & $\%$ & Number & $\%$ & Number & $\%$ & & \\
\hline \multicolumn{2}{|l|}{ Age } & \multicolumn{2}{|c|}{$51.37 \pm 8.356$} & \multicolumn{2}{|c|}{$54.63 \pm 7.286$} & \multicolumn{2}{|c|}{$53.22 \pm 7.885$} & \multirow{3}{*}{1.463} & \multirow{3}{*}{$0.230^{\mathrm{NS}}$} \\
\hline \multirow[t]{2}{*}{ Sex } & M & 29 & 85.3 & 41 & 87.2 & 70 & 86.4 & & \\
\hline & $\mathrm{F}$ & 5 & 14.7 & 6 & 12.8 & 11 & 13.6 & & \\
\hline \multicolumn{2}{|c|}{ LV EF \% } & \multicolumn{2}{|c|}{$57.97 \pm 4.260$} & \multicolumn{2}{|c|}{$56.72 \pm 6.908$} & & 4.003 & \multicolumn{2}{|l|}{$0.049^{\mathrm{s}}$} \\
\hline CPB & time & \multirow{2}{*}{\multicolumn{2}{|c|}{$\begin{array}{r}135.85 \pm 19.158 \\
35059+91352\end{array}$}} & \multicolumn{2}{|c|}{$145.64 \pm 21.465$} & & 0.009 & \multicolumn{2}{|l|}{$0.924^{\mathrm{NS}}$} \\
\hline \multicolumn{2}{|c|}{ Bleeding } & & & \multicolumn{2}{|c|}{$470.32 \pm 128.174$} & & 4.895 & \multicolumn{2}{|l|}{$0.03^{\mathrm{s}}$} \\
\hline
\end{tabular}

Group A = Pre-operative mean platelet volume $<10.6 \mathrm{fL}$, Group B = Pre-operative mean platelet volume $£ 10.6 \mathrm{fL}$; NS = Not significant, $\mathrm{S}=$ significant, $\mathrm{M}=$ Male, $\mathrm{F}=$ Female

Table-II

Adverse events observed in study patients

\begin{tabular}{|c|c|c|c|c|c|c|c|c|}
\hline \multirow[t]{2}{*}{ Characteristics } & \multicolumn{2}{|c|}{ Group $A(n=34)$} & \multicolumn{2}{|c|}{ Group B $(n=47$} & \multicolumn{2}{|c|}{ Total $(n=81)$} & \multirow[t]{2}{*}{$3 \mathrm{C} 2$} & \multirow[t]{2}{*}{$\mathrm{p}$ value } \\
\hline & Number & $\%$ & Number & $\%$ & Number & $\%$ & & \\
\hline \multicolumn{9}{|c|}{ Post - operative Ml } \\
\hline No & 31 & 88.2 & 39 & 85.1 & 70 & 86.4 & 4.99 & $0.028^{5}$ \\
\hline Yes & 3 & 11.8 & 8 & 14.9 & 11 & 13.6 & & \\
\hline \multicolumn{9}{|c|}{ Post-operative arrhythmia } \\
\hline No & 31 & 91.2 & 41 & 87.2 & 72 & 88.9 & $0.040 *$ & $0.842^{\mathrm{NS}}$ \\
\hline Yes & 3 & 8.8 & 6 & 12.8 & 9 & 11.1 & & \\
\hline \multicolumn{9}{|c|}{ Post-operative state } \\
\hline Alive & 34 & 100.0 & 44 & 93.6 & 78 & 96.3 & $0.819 *$ & $0.365^{\mathrm{Nb}}$ \\
\hline Death & 0 & 0.0 & 3 & 6.4 & 3 & 3.7 & & \\
\hline \multicolumn{9}{|c|}{ Post-operative bleeding } \\
\hline Upto $500 \mathrm{ml}$ & 32 & 94.1 & 34 & 72.3 & 66 & 81.5 & $4.84 *$ & $0.028^{\mathrm{s}}$ \\
\hline$>500 \mathrm{ml}$ & 2 & 5.9 & 13 & 27.7 & 15 & 18.5 & & \\
\hline
\end{tabular}

Continuity correction. Group A = Pre-operative mean platelet volume $<10.6 \mathrm{fl}$, Group B = Pre-operative mean platelet volume $>10.6 \mathrm{fl}$; NS = Not significant, $\mathrm{S}=$ Significant 


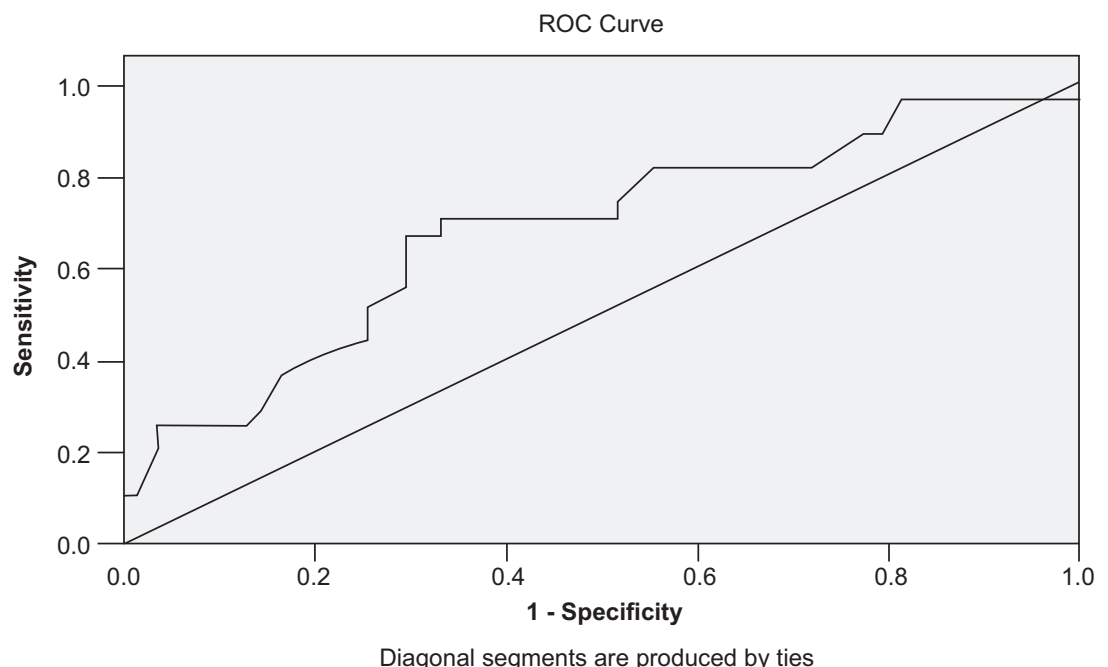

Fig.-1: A receiver-operating characteristics (ROC) curve of MPV of the study sample for the prediction of post $C A B G$ adverse events

Table-III

Univariate analysis of adverse events of study population

\begin{tabular}{|c|c|c|c|c|c|c|c|c|}
\hline \multirow[t]{2}{*}{ Characteristics } & \multirow[b]{2}{*}{$\mathrm{No}=54$} & \multicolumn{2}{|c|}{ Averse Events } & \multicolumn{2}{|c|}{ Total $(\mathrm{n}=81)$} & \multirow{2}{*}{$\begin{array}{c}5 \mathrm{C} 2 \\
\%\end{array}$} & \multirow[t]{2}{*}{ p value } & \\
\hline & & $\%$ & Yes $=27$ & $\%$ & Number & & & \\
\hline \multicolumn{9}{|l|}{$\overline{\operatorname{Sex}}$} \\
\hline Male & 47 & 87.0 & 23 & 85.2 & 70 & 86.4 & \multirow[t]{3}{*}{$0.053^{*}$} & \multirow[t]{2}{*}{$0.819^{\mathrm{NS}}$} \\
\hline Female & 7 & $1.3-0$ & 4 & 14.8 & 11 & 13.6 & & \\
\hline \multicolumn{8}{|l|}{ LVEF\% } & \\
\hline$<50$ & 3 & 5.6 & 6 & 22.2 & 9 & 11.1 & \multirow[t]{3}{*}{$2.975 * *$} & \multirow[t]{3}{*}{$0.037^{\mathrm{s}}$} \\
\hline $51-60$ & 28 & 51.8 & 17 & 63.0 & 45 & 55.6 & & \\
\hline$>60$ & 23 & 42.6 & 4 & 14.8 & 27 & 33.3 & & \\
\hline \multicolumn{9}{|l|}{ MPV } \\
\hline$>10.6$ & 28 & 51.9 & 6 & 22.2 & 34 & 42.0 & \multirow[t]{2}{*}{6.488} & \multirow[t]{2}{*}{$0.011^{\mathrm{s}}$} \\
\hline$>10.6$ & 26 & 55.3 & 21 & 77.8 & 47 & 58.0 & & \\
\hline \multicolumn{9}{|c|}{ No of bypass graft } \\
\hline 1 & 1 & 1.9 & 0 & 0.0 & 1 & 1.2 & \multirow[t]{4}{*}{$2.061^{*}$} & \multirow[t]{4}{*}{$0.560^{\mathrm{NS}}$} \\
\hline 2 & 8 & 7.4 & 2 & 7.4 & 10 & 12.3 & & \\
\hline 3 & 44 & 92.6 & 25 & 92.6 & 69 & 85.3 & & \\
\hline 4 & 0 & 0.0 & 1 & 0.0 & 1 & 1.2 & & \\
\hline \multicolumn{9}{|c|}{ Cardio-pulmonary bypass time (min) } \\
\hline$<115$ & 8 & 14.8 & 1 & 3.7 & 9 & 11.1 & \multirow[t]{5}{*}{$3.106 * *$} & \multirow[t]{5}{*}{$0.035^{\wedge}$} \\
\hline $116-135$ & 13 & 24.1 & 4 & 14.9 & 17 & 21.0 & & \\
\hline $136-155$ & 23 & 42.6 & 13 & 48.1 & 36 & 44.4 & & \\
\hline$>155$ & 10 & 18.5 & 9 & 33.3 & 19 & 23.5 & & \\
\hline Mean \pm SD & 138 & 22.635 & 148.52 & 5.237 & & & & \\
\hline
\end{tabular}

Continuity correction **ANOVAtest; $\mathrm{NS}=$ Not significant, $\mathrm{S}=$ Significant

Table-IV

\begin{tabular}{lcccc}
\hline Independent Variable & Standardized Coeficient (p) & OR & $95 \% \mathrm{Cl}$ & P value \\
\hline Constant & -2.645 & - & - & - \\
Preoperative mean platelet volume (MPV) (fL) & 0.686 & 1.968 & $1.193-3.305$ & $0.008^{\mathrm{s}}$ \\
LVEF\% & -0.123 & 0.884 & $0.799-0.979$ & $0.058^{\mathrm{NS}}$ \\
CPB in min & 0.010 & 1.010 & $0.979-1.042$ & $0.527^{\mathrm{Nb}}$ \\
\hline
\end{tabular}

$\mathrm{S}=$ Significant, $\mathrm{NS}=$ Not Significant 
In logistic regression analysis mean platelet volume found strong predictor of early major adverse event after CABG surgery $(\mathrm{OR}=1.968$ including $95 \% \mathrm{Cl} 1.193$ 3.305 and $\mathrm{p}=0.008)$.

\section{Discussion:}

A total 34 patients who has MPV $<10.60 \mathrm{fl}$ _ were included in group A and a total of 47 patients who has MPV $>10.6 \mathrm{fl}$ _ were included in group B. The mean age of the studied patients were 53.22 \pm 7.88 years ranging from 32 to 70 years. It was found that middle aged people are most commonly underwent $\mathrm{CABG}$ surgery in this study. Maximum patients $69(85.2 \%)$ of this study had triple vessel disease and maximum patients $69(85.2 \%)$ in this study were given 3 grafts.

Mean CPB time in group A and group B was observed $135.85 \pm 19.158$ and $145.64 \pm 21.465 \mathrm{w}$ minutes respectively.

Regarding post-operative arrhythmia and post-operative death no significant association was found in between the groups $(p>0.05)$. Strong association of post-operative Ml $(\mathrm{p}<0.05)$ and post-operative bleeding was found between the groups $(\mathrm{p}<0.05)$. Metabolically and enzymatically overactive large platelets cause secretion of prothrombotic materials and ultimately thrombotic occlusion of coronary vessels or bypass grafts. This is the reason of increased no. of postoperative Ml. On the other hand CPB related haemodilution, platelet dysfunction, altered platelet force generation, reduced aggregation due to hypothermia and heparin binding stimulation of fibrinolytic system all contribute to increase incidence of bleeding in elevated MPV group B.

During the follow-up after CABG operation, combined adverse events occurred in 27 patients (33.3\%). This is an acceptable range of adverse events as it is estimated combined. In my study mortality is $3.7 \%$. Statistically significant association of adverse events were found between group A and group B in the study population $(p=0.011)$. Univariate analysis showed statistically significant difference of left ventricular ejection fraction (LVEF), Mean platelet volume (MPV) and total cardio pulmonary bypass time (CPB) with post $\mathrm{CABG}$ adverse events $(\mathrm{p}=0.037, \mathrm{p}=0.011, \mathrm{p}=0.035$ respectively). ROC curve of MPV for predicting post CABG adverse events at $10.60 \mathrm{fL}$ cut off point sensitivity $77.48 \%$ and specificity $63.6 \%$. This cut off point level will further guide us for predicting outcome.

In logistic regression analysis mean platelet volume found strong predictor of early postoperative major adverse events after $\mathrm{CABG}$ surgery $(\mathrm{OR}=1.968$ including
$95 \% \mathrm{Cl} 1.193-3.305$ and $\mathrm{p}=0.008)$. This finding indicates the independent predictive value of the preoperative MPV level with post-CABG adverse events.

MPV baseline values vary in different population groups and in different geographical areas (Kumar et al 2013). There has always been a need to establish baseline hematological values of indigenous population. Due to lack of standard local reference values we rely on normal standards of western countries. Our aim was to establish reference MPV values for predicting early outcomes in our population group. During CABG surgery if we pay attention to this elevated MPV we could avoids adverse effects and save many lives.

\section{Conclusion:}

To the best of our knowledge, this is the first study in our country that the MPV level is evaluated for the adverse outcomes after CABG. Preoperative elevated MPV level was associated and a strong independent predictor only with combined adverse events. Mean platelet volume is an important, simple, readily available, and cost effective tool. MPV is obtained by routine investigation Complete Blood Count (CBC). CBC is done to every patient as a part of preoperative preparation and can be useful in predicting the postoperative adverse events in patients undergoing CABG surgery by MPV. So that early precaution can be taken for prevention of those adverse events and appropriate management can be arranged.

\section{References:}

1. Anna, H., Madeleine, N., Benjamin, B. and Richard, S. Outcomes of coronary artery bypass graft surgery. Vascular Health Risk Management, 2006;52(9):477-84.

2. Chu, S.G., Becker, R.C., Berger, P.B., Bhatt, D.L. \& Eikelboom, J.W. Mean platelet volume as a predictor of cardiovascular risk: a systematic review and meta-analysis. Journal of Thrombo Haemostasis, 2010;48(2):148-56.

3. Davi, G. \& Patrono, C. Platelet activation and atherothrombosis. New England Journal of Medicine. 2007;357:2482-94.

4. Gurbel, P.A., Mahla, E. \& Tantry, U.S. Peri-operative platelet function testing: the potential for reducing ischaemic and bleeding risks. Journal of Thrombosis and Haemostat, 2011;106(4):248-52.

5. Martin, J.F., Bath, P.M. \& Burr, M.L. Influence of platelet size on outcome after myocardial infarction. Lancet, 1991;338(11):1409-11.

6. Unal, E.U., Anil, O., Sabit, K. \& Ahmet, B.D. Mean platelet volume may predict early clinical outcome after coronary artery bypass grafting. Journal of Cardiothoracic Surgery, 2013;8:91.

7. Wagner, D.D. and Burger, P.C. Platelets in inflammation and thrombosis, Arteriosclerosis and Thrombotic Vascular Biology, 2003;23:2131-37.

8. Wang, R.T., Li, Y., Zhu, X.Y. \& Zhang, Y.N. Increased mean platelet volume is associated with arterial stiffness. Platelets, 2011;2: 447-51. 